\title{
Fire protection systems using clay-gypsum plaster in agriculture
}

\author{
Marat Asamatdinov ${ }^{1}$, Alexey Zhukov ${ }^{2, *}$, Andrey Medvedev², Vitaly Mukhametzyanov ${ }^{2}$ \\ ${ }^{1}$ Karakalpak State University named after Berdakh, Abdirov street, 230112, Nukus, Uzbekistan \\ ${ }^{2}$ Moscow State University of Civil Engineering, 26, Yaroslavskoye Shosse, 129337, Moscow, Russia
}

\begin{abstract}
The article substantiates using a modified binder based on claygypsum as the main component of dispersed reinforced and plasters mixtures. The rheological properties of such mixtures and the performance characteristics of plaster coatings have been studied. It is proved that the use of clay gypsum as part of a modified dispersed reinforced binder contributes to the creation of favorable environmental conditions and the formation of a comfortable climate inside the agricultural premises, as well as increases the degree of protection of structures in fire conditions. It is established that the technological properties of dispersed reinforced plaster mixtures depend primarily on the composition of the modified claygypsum binder and the consumption of mineral fiber and its length. The fiber diameter within 3.2-3.4 microns does not significantly affect the properties of mixtures. Dispersed reinforcement in the range from 1 to $5 \%$ slightly affects the average density of clay-gypsum mixtures and plaster coatings based on them. Dispersed reinforcement has the greatest effect on the mobility of the mortar plaster mixture and, to a lesser extent, on its thixotropy. The introduction of mineral fibers has a significant impact on the strength characteristics of plaster coatings, and, to the greatest extent, on the strength of bending, the compressive strength is most affected by the content of semi-aqueous gypsum in the composite binder. An increase in bending strength by $20 \%$ determines the greater resistance of plaster coatings to temperature influence and this allows us to state an increase in the duration of the functioning of clay plaster barriers when protecting load-bearing structures and insulation systems from the effects of high temperatures.
\end{abstract}

\section{Introduction}

Building mixes based on gypsum binders are widely used in complete interior finishing systems: putties, primers, adhesives, plasters. In domestic construction, interior finishing mixes of KNAUF, Saint Gobain (WEBER), and other companies are used [1, 2]. Gypsumcontaining finishing compositions in addition to decorative expressiveness and good workability have a number of features that increase their attractiveness. In the first, it is the ability to absorb excess moisture and secretions from the indoor air and release them in the process of airing the room. Secondly, it can be used as a barrier to fire protection. This

* Corresponding author: 1j211@yandex.ru 
feature is implemented in drywall fire resistant sheets. In these sheets, fire resistance is increased by dispersed reinforcement of the gypsum matrix by introducing chopped glass fiber [3].

particular interest is the use of products based on modified gypsum binder, gypsumcontaining waste products and gypsum binder based on local raw materials in the interior decoration of wet rooms or in the external lining of building structures [4]. Gypsum binder is not cheap, and in some areas is a scarce building material (semi-finished product). Because of it in the MCSU and KSU named after Berdah (Karakalpak State University) research is being conducted to study the possibility of using local binders for partial replacement of gypsum. One possibility is the use of clay gypsum.

Clay gypsum - rock of sedimentary origin containing gypsum, clay fraction, silica, alumina, and etc. According to their composition, clay gypsum is a natural building composite because it is a relatively dense conglomerate consisting of calcium sulfate semihydrate (gypsum), clay minerals, silica, and other impurities. Available information about the results of studying this material in the 40-50s of the 20th century showed that on the basis of clay gypsum, it is potentially possible to obtain a gypsum binder with various properties. However, the industrial use of clay gypsum has not been organized, this is due to the lack of knowledge of raw materials and products obtained from it [5].

Binders made of clay gypsum have not been used for a long time due to the lack of knowledge of the technology for its production and further use. The solution to the problem of creating effective clay gypsum binders lies in the planes of creating scientifically based methods for processing raw materials and obtaining modified gypsum binder for building solutions, and, first of all, plaster compositions [6].

The purpose of the research described in the article is to develop recipes and technologies of the use of clay plaster mixes, dispersed reinforced with chopped mineral fiber. To achieve this purpose were formulated two specific tasks: the study of the rheological characteristics of clay-gypsum mixtures with filler and the study of the properties of clay-gypsum plaster coating with dispersed reinforcement.

\section{Materials and Methods}

The main problem when performing plaster works on vertical surfaces is the preliminary determination of the absence of run-off (sliding) of mortar mixtures with different thickness of the applied layer. Such technological factors are evaluated empirically [7].

An indicator of the properties of plaster compositions, defined as "run-off", characterizes the creep of mortar mixtures in thick layers on vertical surfaces and can be modeled by applying a cylindrical layer using a metal cylinder of a preset height [8]. A numerical indicator can be the value of the movement of the lower end of the cylinder prepared from a solution mixture. In plaster compositions that meet the indicator of "no run-off", the displacement of the cylinder should not exceed 0.5 layer thickness for 10 seconds of being in a vertical position.

The value of the maximum shear stress of the LSD is determined on a conical plastometer (Rebinder cone) or on a reference cone according to the method of the standard «Construction solutions. Test methods». Before the measurement of the maximum shear stress and the runoff process, the thixotropic structure of plaster mixtures was extremely destroyed in a high-speed agitator $(400 \div 500 \mathrm{rpm})$.

The experimental assessment of additional requirements for plaster compositions based on clay gypsum in the laboratory is performed as follows. To assess the runoff, a cylinder is taken whose height corresponds to the maximum thickness of the applied layer. The inner surface of the cylinder is lubricated with engine oil. The cylinder is placed on a horizontally installed concrete slab and filled with a liquid mixture with mobility of PK3 $(8-12 \mathrm{~cm})$. The 
cylinder is carefully lifted up and taken aside. The concrete slab is installed vertically (Fig. 1 ). Within 10 seconds the movement of the lower end of the cylindrical shape of the sample relative to the initial position is evaluated. It is considered that there is no runoff if the outer lower end of the cylinder has shifted no more than $50 \%$ of the layer thickness. At the same time, the maximum shear stress on the reference cone is evaluated.

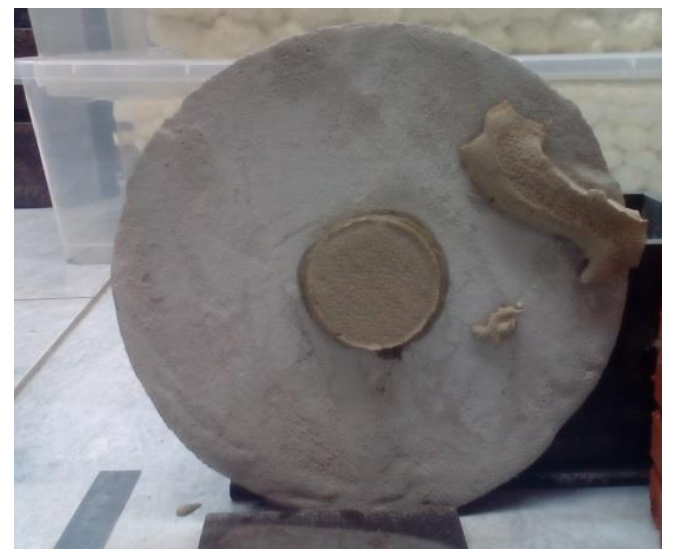

Fig. 1. Estimation of runoff of a clay-gypsum mixture reinforced with fiber from a concrete base.

The study of the performance characteristics of clay gypsum dispersed reinforced plaster mixtures was carried out using the methodology of mathematical planning of the experiment [9-11], the conditions of which are presented in table 1. The following indicators are accepted as variable factors like The content of gypsum in the composite binder (X1), the consumption, and length of the chopped mineral fiber ( $\mathrm{x} 2$ and $\mathrm{X} 3$, respectively). The compressive strength (Y1), MPa; the bending strength (Y2), MPa; and the average density of clay gypsum dispersed reinforced plaster (Y3), $\mathrm{kg} / \mathrm{m} 3$ are accepted as the response functions. The average diameter of mineral fibers in the experiment was assumed to be constant in the range of 3.2-3.4 microns.

Table 1. The conditions of the experiment.

\begin{tabular}{|l|c|c|c|c|c|}
\hline Name of the factor & SymbolX & \multirow{2}{*}{$\begin{array}{l}\text { Average value } \\
\text { of the factor, } \bar{X}_{\mathbf{i}}\end{array}$} & $\begin{array}{l}\text { Variation } \\
\text { range, } \Delta \mathbf{X}_{\mathbf{i}}\end{array}$ & \multicolumn{2}{|c|}{$\begin{array}{l}\text { The values of the } \\
\text { factor on levels }\end{array}$} \\
\cline { 4 - 6 } & & 75 & 15 & 60 & 90 \\
\hline $\begin{array}{l}\text { Gypsum content in the } \\
\text { composite binder, \% }\end{array}$ & $\mathrm{X}_{1}$ & 3 & 2 & 1 & 5 \\
\hline $\begin{array}{l}\text { Consumption of fibers, \% } \\
\text { by weight of the binder }\end{array}$ & $\mathrm{X}_{2}$ & 4 & 2 & 2 & 6 \\
\hline $\begin{array}{l}\text { Length of chopped fiber, } \\
\text { mm }\end{array}$ & $\mathrm{X}_{3}$ & 4 & & \\
\hline
\end{tabular}

In natural clay gypsum, depending on the Deposit, the content of semi-aqueous gypsum is from 60 to $90 \%$. The other part is represented by clay minerals, amorphous silica of sand and dust fractions, and other inert components. The experiment used model, artificially prepared compositions with the same content of semi-aqueous gypsum.

\section{Experimental \& Results}

As test samples, plaster compositions based on a clay-gypsum binder reinforced with glass or basalt mineral fiber were used. The water-solid relations were established based on the results of previously given experiments performed for clay plaster compositions [12]. 
Before measurement, in both cases, the thixotropic structure of the mortar mixture is completely destroyed by mixing. The results of experiments at $\mathrm{W} / \mathrm{S}=0.48$ and the density of the plaster mixture $1420 \mathrm{~kg} / \mathrm{m} 3$ and the layer thickness $\delta=20 \mathrm{~mm}$ are presented in table 2.

Table 2. Results of determination of rheological characteristics of plaster solutions with dispersed reinforcement of mixtures.

\begin{tabular}{|c|c|c|c|}
\hline \multirow{2}{*}{$\begin{array}{c}\text { Consumption of } \\
\text { mineral fiber }\end{array}$} & \multicolumn{2}{|c|}{ Ultimate shear stress $\boldsymbol{\tau}_{\boldsymbol{s h}}, \frac{\boldsymbol{g}}{\mathbf{c m}^{\mathbf{2}}}$} & $\begin{array}{c}\text { Lower end shift } \boldsymbol{\Delta} \text { in } \mathbf{1 0} \text { sec, } \\
\text { mm }\end{array}$ \\
\hline 1 & $\tau_{\boldsymbol{s} h} \mathbf{1}, \mathbf{s e c}$ & $\tau_{\boldsymbol{s} h} \mathbf{1 0}, \mathbf{s e c}$ & 6 \\
\hline 3 & 4.3 & 4.4 & 5 \\
\hline 5 & 4.4 & 4.5 & 4 \\
\hline
\end{tabular}

In order to select the optimal composition of plaster, mixtures tests were conducted to determine the influence of various parameters on the thixotropic properties of mixtures. The influence of the water-solid ratio on the rheological behavior of the plaster composition based on a clay-gypsum binder was studied.

Optimal plaster mixtures based on clay gypsum can be considered such as with mobility of at least PK3, the maximum shear stress in the first seconds of thixotropic hardening ensures that there is no runoff for a given thickness of the applied layer in a single pass. At PK 3, "sliding" on the concrete surface is no more than $6 \%$. This depends on the density, roughness, absorbency, humidity, degree of contamination and etc.

Taking into account the factor of sliding of the concrete mix from the vertical surface of the base (vertical wall) and rheological characteristics (maximum shear stress), optimal intervals of consumption of the reinforcing component are established. The upper and lower intervals of the water-cement ratio were established as a result of research conducted earlier.

The results of studying the rheological characteristics of dispersed-reinforced mixtures were used in the development of the plan of conduct using the method of mathematical planning. Implementation of the experiment allowed us to obtain the following regression equations. Confidence intervals $(\Delta b)$ are established during to statistical processing of experiment results.

Compressive strength of dispersed reinforced clay gypsum plaster (Rc, Y1):

$Y_{1}=6,8+1,8 \mathrm{X}_{1}+1,1 \mathrm{X}_{2}+0,9 \mathrm{X}_{3}+0,6 \mathrm{X}_{2} \mathrm{X}_{3}$

$\Delta b_{1}=0,4 \mathrm{MPa}$

Strength limit of dispersed reinforced clay gypsum plaster when bending $\left(R_{\mathrm{b}}, Y_{2}\right)$ :

$Y_{2}=3,6+0,5 \mathrm{X}_{1}+1,4 \mathrm{X}_{2}+1,1 \mathrm{X}_{3}+0,6 \mathrm{X}_{2} \mathrm{X}_{3}$

$\Delta b_{2}=0,3 \mathrm{MPa}$

Average density of dispersed reinforced clay gypsum plaster $\left(\rho_{\mathrm{cg}}, Y_{3}\right)$ :

$Y_{3}=1060+38 \mathrm{X}_{1}+24 \mathrm{X}_{2}+16 \mathrm{X}_{3}-16 \mathrm{X}_{2}^{2}$

$\Delta b_{3}=12 \kappa \Gamma / \mathrm{M}^{3}$

The optimal value of fiber consumption is determined using the analytical optimization method by determining the partial derivative of the regression equation $\mathrm{Y} 3=\mathrm{f}(\mathrm{X} 1, \mathrm{x} 2, \mathrm{X} 3)$ and equating the differentiation result to 0 . The optimal value determined analytically $(\mathrm{x} 2=$ 0.75 ) is inserted into the regression equations and the equations optimized for $\mathrm{x} 2$ are obtained.

Optimized compressive strength of plaster $\left(R_{\mathrm{c}}, Y_{1}\right)$ :

$Y_{1}=7,6+1,8 \mathrm{X}_{1}+1,3 \mathrm{X}_{3}$

Optimized the tensile strength of the plaster while bending $\left(R_{\mathrm{b}}, Y_{2}\right)$ :

$Y_{2}=4,5+0,5 \mathrm{X}_{1}+1,5 \mathrm{X}_{3}$

Optimized average density of plaster $\left(\rho_{\mathrm{d}}, Y_{3}\right)$ :

$Y_{3}=867+18 \mathrm{X}_{1}+10 \mathrm{X}_{3}$ 
The optimized equations are linear dependencies of responses from variable factors, which makes it easier to use them when solving problems of selecting the composition of clay gypsum dispersed reinforced plaster mixtures. The natural value of the factor used for optimization is calculated using the data in table 1. The optimal consumption of mineral fiber is $4.5 \%$ of the weight of the binder.

Solving problems of predicting the properties of dispersed reinforced mixtures and plaster coatings based on them is also possible by creating computer programs and calculating parameters based on them.

\section{Discussion}

Experiments have shown that dispersed reinforcement with chopped mineral fiber affects the rheological characteristics of clay-gypsum mixtures and has an ambiguous effect on the properties of plaster coatings. The type of mineral fiber (glass or basalt) does not significantly affect the properties of mixtures and plaster coatings.

Assessment of the thixotropic properties of building solutions on gypsum binders is difficult due to the fact that simultaneously there are processes of thixotropic hardening and hydration of the binder. However, in a time period of 1-10 seconds after the ultimate destruction of the structure of the solution mixture, the process of hydration of the binder can be ignored due to the slow increase in strength. The research shows that the consumption of mineral fiber has a greater effect on the ultimate shear stress of solution mixtures and to a lesser extent on the sliding of these mixtures from vertical surfaces. In the range from 1 to $5 \%$, the effect of fiber consumption on the density of the mixture is insignificant.

Processing of experimental data showed that the consumption and characteristics of the fiber on the average density of the plaster coating have a slight effect, not exceeding $8 \%$. In this case, was set a local extreme for fiber consumption (x2), which was used in solving the optimization problem.

On the density of the mixture, as well as the plaster coating, the effect of fiber consumption in the range from 1 to $5 \%$ is insignificant. The compressive strength is most affected by the content of semi-aqueous gypsum in the composite binder (coefficient at X1), the flow rate and length of the fiber are also significant, but to a lesser extent (coefficient at $\mathrm{x} 2$ and X3). The bending strength is most affected by the consumption of mineral fiber (coefficient at $\mathrm{x} 2$ ), and the content of semi-aqueous gypsum in the binder affects the least (coefficient at X1). When evaluating the influence of variable factors, a synergistic effect of the combined effect of the flow rate and length of mineral fibers was established. This effect is more pronounced for the strength of plaster mixtures when bending, which allows us to state an increase in the duration of the functioning of clay-gypsum plaster barriers when protecting load-bearing structures and insulation systems when protecting against high temperatures

\section{Conclusion}

The use of local building materials is an effective contribution to the economy of mineral resources, which are used for the production of basic building materials - cement, concrete, plaster coatings and etc., which determines their economic and environmental feasibility. Clay gypsum is a local raw material in many regions of the country and some CIS countries. This raw material belongs to the group of sedimentary rocks, lies close to the surface of the earth, which simplifies its extraction. 
Research has shown that dispersed reinforcement in the range from 1 to $5 \%$ has little effect on the average density of clay-gypsum mixtures and plaster coatings based on them. The technological properties of plaster mixes depend on the composition of the modified clay-gypsum binder, as well as the consumption of mineral fiber and its length. The diameter of the fiber does not significantly affect the properties of mixtures.

The introduction of mineral fibers with a diameter of 3.2-3.4 microns has a significant impact on the strength characteristics of plaster coatings, and, in the greatest degree on the strength of bending, compressive strength is most affected by the content of semi-aqueous gypsum in the composite binder. An increase in bending strength by $20 \%$ determines the greater resistance of plaster coatings to temperature effects and, consequently, better protection of load-bearing structures in fire conditions.

The use of clay gypsum as part of a modified dispersed reinforced binder allows us to solve the problem of saturation of the market with local inexpensive materials, contributes to the creation of favorable environmental conditions and the formation of a comfortable indoor climate, as well as increases the degree of protection of structures in fire conditions.

\section{References}

1. A.D. Zhukov, V.S. Semenov, I.J. Gnip, S.J. Vaitkus, MATEC Web of Conferences 117(24), 0018426 (2017)

2. P.M. Zhuk, A.D. Zhukov, Ecology and Industry of Russia 4, 52-57 (2018)

3. D. Tuchaev, E. Zarmanyan, E. Petrovskiy, A. Zemlyanko, K. Ivanov, A. Zhukov, IOP Conf. Series: Materials Science and Engineering (2018) DOI:10.1088/1757899X/365/3/032015032041

4. B.M. Rumiantcev, A.D. Zhukov, D.B. Zelenshikov, A.S. Chkunin, K.K. Ivanov, Yu.V. Sazonova, MATEC Web of Conferences $\mathbf{8 6}$ (2016) DOI: http://dx.doi.org/10.1051/matecconf/ 20168604027

5. A.D. Zhukov, K.A. Ter-Zakaryan, V.S. Semenov, S.D. Kozlov, E.A. Zinovieva, E.D. Fomina, IPICSE (2018) DOI: https://doi.org/10.1051/matecconf/201825101014

6. I.J. Gnip, V.J. Keršulis, S.J. Vaitkus, Mechanics of Composite materials 41(4), 357364 (2005)

7. V.S. Semenov, K.A. Ter-Zakaryan, A.D. Zhukov, Yu.V. Sazonova, Building materials 4, 65-69 (2018) DOI: https://doi.org/10.31659/0585-430X-2018-758-4-65-69

8. A.D. Zhukov, K.A. Ter-Zakaryan, I.V. Bessonov, V.S. Semenov, A.V. Starostin, Building materials 9, 58-61 (2018) DOI: https://doi.org/10.31659/0585-430X-2018763-9-58-61

9. E.A. Zinovieva, A.D. Zhukov, A.K. Ter-Zakaryan, I.V. Bessonov, Housing 7, 35-40 (2019) DOI: https://doi.org/10.31659/0044-4472-2019-7-35-40

10. O.I. Rubtsov, E.Yu. Bobrova, A.D. Zhukov, E.A. Zinovieva, Building materials 9, 813 (2019) DOI: https://doi.org/10.31659/0585-430X-2019-774-9-8-13

11. A.D. Zhukov, K.A. Ter-Zakaryan, A.D. Chernov, E.O. Bezverkhova, V.I. Krashchenko, IACJ. International Agricultural Journal 3 (2019) DOI: 10.24411 / 2588 0209-2019-10075

12. N. Umnyakova, I. Bessonov, A. Zhukov, E. Zinoveva, MATEC Web of Conferences (ICMTMTE 2019) (2019) DOI: https://doi.org/10.1051/matecconf/201929800013 